\title{
Dependence of Spreading and Differentiation of Mesenchymal Stem Cells on Micropatterned Surface Area
}

\author{
Wei Song, ${ }^{1,2}$ Naoki Kawazoe, ${ }^{1,3}$ and Guoping Chen ${ }^{1,2,3}$ \\ ${ }^{1}$ Biomaterials Center, National Institute for Materials Science, 1-1 Namiki, Tsukuba, Ibaraki 305-0044, Japan \\ ${ }^{2}$ Graduate School of Pure and Applied Sciences, University of Tsukuba, 1-1-1 Tennodai, Tsukuba, Ibaraki 305-8571, Japan \\ ${ }^{3}$ International Center for Materials Nanoarchitectonics (MANA), National Institute for Materials Science, 1-1 Namiki, \\ Tsukuba, Ibaraki 305-0044, Japan \\ Correspondence should be addressed to Guoping Chen, guoping.chen@nims.go.jp
}

Received 16 October 2010; Revised 6 January 2011; Accepted 5 February 2011

Academic Editor: Yanan Du

Copyright ( $) 2011$ Wei Song et al. This is an open access article distributed under the Creative Commons Attribution License, which permits unrestricted use, distribution, and reproduction in any medium, provided the original work is properly cited.

Micropatterning technology is a highly advantageous approach for directly assessing and comparing the effects of different factors on stem cell functions. In this study, poly(vinyl alcohol)- (PVA-) micropatterned polystyrene surfaces were prepared using photoreactive PVA and ultraviolet photolithography with a photomask. The micropatterned surface was suitable for single-cell array formation and long-term cell culture due to the nanometer thickness of nonadhesive PVA layer. Different degrees of cell spreading with the same cell shape were established by adjusting the sizes of circular, cell-adhesive polystyrene micropatterns. Cell spreading and differentiation of mesenchymal stem cells (MSCs) on the micropatterns were investigated at the single-cell level. The assembly and organization of the cytoskeleton were regulated by the degree of cell spreading. Individual MSCs on large circular micropatterns exhibited a more highly ordered arrangement of actin filaments than did those on the small circular micropatterns. Furthermore, the differentiation of MSCs was dependent on the degree of cell spreading. Increased cell spreading facilitated the osteogenic differentiation but suppressed the adipogenic differentiation of MSCs. This micropatterning method is valuable for stem cell research in tissue engineering and regenerative medicine.

\section{Introduction}

Stem cells, a reservoir of undifferentiated cells with the capacity for unlimited or prolonged self-renewal, have the potential to produce differentiated and specialized progenies [1]. They hold the key to a number of cellular processes, including development, tissue regeneration, and aging, and the promise of cures for many diseases and injuries. They are a versatile and promising cell source for tissue engineering and regenerative medicine [2].

The inherent plasticity and multilineage potential of stem cells have brought about the requirement for strictly controlling cell functions, such as growth, phenotypic expression, and differentiation [3-7]. Traditionally, the fate of stem cells has been regulated by biological factors, such as cytokines and growth factors [8-11]. Recently, more and more evidence has revealed that physical factors also contribute to the overall behaviors and functions of stem cells [12-16]. The area of cell spreading is one such physical factor that has been demonstrated to affect cell behaviors and functions. Bhadriraju and Hansen [17] have reported that the stiffness of hepatocytes is affected by cell spreading. Cell stiffness increases with cell spreading but remains low in cells with round morphology. Szabo et al. [18] have demonstrated the high adipogenic potential of wild-type embryonic stem cells (ESCs) on non-adhesive substrata, where cell spreading is hindered. However, during routine cell culture, the process of cell spreading is often accompanied by a change in cell shape, the area of cell spreading is diverse among cells, and the heterogeneity within a cell population, such as cell-cell interaction, is complex. Therefore, a convenient method for strictly controlling the spreading area of a large number of individual cells with the same shape is extremely desirable for investigating the effect of cell spreading on cell functions.

Micropatterning technology [19] is particularly suitable for this purpose and is already used for investigating the 
effects of physical parameters on cell behaviors, such as the orientation of the cell division axis [20], cell polarization [21, 22], proliferation [23], apoptosis [24], and differentiation [25]. However, one of the main obstacles in applying cell micropatterning technologies is that few of them are compatible with long-term cell culture. Extended culture time is normally required because many cell functions, such as differentiation, need a long time to respond to external stimuli.

In this study, we prepared poly(vinyl alcohol)- (PVA-) micropatterned polystyrene surfaces using ultraviolet photolithography with a photomask. This method is simple and reproducible. The micropatterned surfaces were used to culture mesenchymal stem cells (MSCs), form a stable cell array at the single-cell level for long-term cell culture, and compare the effect of cell spreading on the adipogenic and osteogenic differentiation of MSCs.

\section{Materials and Methods}

2.1. Synthesis of Azidophenyl-Derivatized Poly(vinyl alcohol). Azidophenyl-derivatized poly(vinyl alcohol) (AzPhPVA) was synthesized by coupling the hydroxyl groups of PVA to 4azidobenzoic acid, as previously described [26, 27].

2.2. Micropatterning of Poly(vinyl alcohol). A polystyrene plate was cut from a polystyrene tissue culture flask (BD Falcon). The AzPhPVA solution $(0.15 \mathrm{~mL}, 0.3 \mathrm{mg} / \mathrm{mL})$ was placed on the polystyrene plate and air-dried in the dark at room temperature. The plate was covered with a photomask with UV blocking circular micropatterns of different areas and irradiated with UV light (Funa-UV-Linker FS-1500) at an energy of $0.2 \mathrm{~J} / \mathrm{cm}^{2}$ from a distance of $15 \mathrm{~cm}$. After irradiation, the plate was immersed in MilliQ water and then ultrasonicated to completely remove any unreacted polymer from the unirradiated areas. After washing completely, the PVA-micropatterned surface was obtained.

2.3. Observation by Atomic Force Microscope (AFM). The surface topography of the PVA-micropatterned polystyrene plate was observed using an MFP-3D-BIO atomic force microscope (Asylum Research). A commercially available cantilever (spring constant: $0.06 \mathrm{~N} / \mathrm{m}$; oscillation frequency: $12-24 \mathrm{kHz}$; DNP, Veeco Probes) with a silicon nitride tip was used to measure the samples $\left(90 \times 90 \mu \mathrm{m}^{2}\right)$ in MilliQ water in contact mode. The diameter and thickness of the circular micropattern were measured by section analysis of the acquired image. Three randomly selected micropatterns were measured to calculate the means and standard deviations.

2.4. Cell Culture. Human bone marrow-derived mesenchymal stem cells (hMSCs) were obtained from Osiris Therapeutics (Columbia, MD) at passage 2. The cells were seeded in culture flasks using proliferation medium purchased from Lonza. The proliferation medium contained $440 \mathrm{~mL}$ of MSC basal medium, $50 \mathrm{~mL}$ of mesenchymal cell growth supplement, $10 \mathrm{~mL}$ of $200 \mathrm{mM}$ L-glutamine, and $0.5 \mathrm{~mL}$ of a penicillin/streptomycin mixture. The cells were further subcultured once after reaching confluence and used at passage 4 . The cells were collected by treatment with trypsin/EDTA solution and suspended in control medium at a density of $1.5 \times 10^{4}$ cells $/ \mathrm{mL}$. The control medium was composed of Dulbecco's modified Eagle's medium (DMEM, Sigma) supplemented with $4500 \mathrm{mg} / \mathrm{L}$ glucose, $584 \mathrm{mg} / \mathrm{L}$ glutamine, $100 \mathrm{U} / \mathrm{mL}$ penicillin, $100 \mu \mathrm{g} / \mathrm{mL}$ streptomycin, $0.1 \mathrm{mM}$ nonessential amino acids, $0.4 \mathrm{mM}$ proline, $50 \mathrm{mg} / \mathrm{L}$ ascorbic acid, and 10\% fetal bovine serum (FBS). The micropatterned polystyrene plates were placed in 6-well cell culture plates, and a glass ring (diameter: $15 \mathrm{~mm}$; height: $10 \mathrm{~mm}$ ) was placed over each PVA micropatterned polystyrene plate. Three milliliters of control medium were added to each well, and then the cell suspension solution $\left(0.36 \mathrm{~mL}, 1.5 \times 10^{4}\right.$ cells $\left./ \mathrm{mL}\right)$ was placed inside the glass ring (seeding density: $3.0 \times 10^{3}$ cells $/ \mathrm{cm}^{2}$ ). After $6 \mathrm{~h}$, the glass rings were removed, and the control medium was replaced with adipogenic or osteogenic medium. The adipogenic medium consisted of DMEM supplemented with $4500 \mathrm{mg} / \mathrm{L}$ glucose, $584 \mathrm{mg} / \mathrm{L}$ glutamine, $100 \mathrm{U} / \mathrm{mL}$ penicillin, $100 \mu \mathrm{g} / \mathrm{mL}$ streptomycin, $0.1 \mathrm{mM}$ nonessential amino acids, $0.4 \mathrm{mM}$ proline, $50 \mathrm{mg} / \mathrm{L}$ ascorbic acid, $10 \% \mathrm{FBS}, 1 \mathrm{M}$ dexamethasone, $0.5 \mathrm{mM}$ methylisobutylxanthine, $10 \mu \mathrm{g} / \mathrm{mL}$ insulin, and $100 \mu \mathrm{M}$ indomethacin. The osteogenic medium consisted of DMEM supplemented with $1000 \mathrm{mg} / \mathrm{L}$ glucose, $584 \mathrm{mg} / \mathrm{L}$ glutamine, $100 \mathrm{U} / \mathrm{mL}$ penicillin, $100 \mu \mathrm{g} / \mathrm{mL}$ streptomycin, $0.1 \mathrm{mM}$ nonessential amino acids, $50 \mathrm{mg} / \mathrm{L}$ ascorbic acid, $10 \%$ FBS, $100 \mathrm{nM}$ dexamethasone, and $10 \mathrm{mM} \beta$ glycerophosphate disodium salt hydrate. The adipogenic and osteogenic media were changed every 3 days.

2.5. F-Actin Staining. After incubation for $6 \mathrm{~h}$ in control medium, the cultured cells were fixed with $4 \%$ paraformaldehyde, permeabilized with $0.2 \%$ Triton X-100, and blocked with $1 \%$ BSA solution. The F-actin and nuclei of cells were stained with Alexa Fluor 488 phalloidin (Invitrogen) and 4',6-diamidino-2-phenylindole (DAPI, Vector Laboratories, Inc.), respectively. Fluorescence photographs of the stained MSCs were captured by an Olympus BX51 microscope with a DP-70 CCD camera (Olympus, Tokyo, Japan).

2.6. Oil Red O Staining. After incubation in adipogenic induction medium for 7 days, the cultured cells were fixed with $4 \%$ paraformaldehyde, incubated in $60 \%$ isopropanol for $5 \mathrm{~min}$, and then stained with fresh Oil Red $\mathrm{O}$ for $5 \mathrm{~min}$. The Oil Red $\mathrm{O}$ solution was prepared by mixing three parts stock solution, $0.3 \%$ in isopropanol with two parts MilliQ water and filtering through a $0.2-\mu \mathrm{m}$ filter. Photomicrographs were captured by an optical microscope with a DP-70 CCD camera (Olympus, Tokyo, Japan). The probability of MSC adipogenesis at different cell spreading areas was studied by calculating the percentage of MSCs that committed to an adipocyte lineage. MSCs containing lipid vacuoles positively stained by Oil Red $\mathrm{O}$ were considered to be adipocytes, and only single cells on each circular micropattern (as confirmed by nuclear staining) were counted. Three samples were used to calculate the means and standard deviations. 

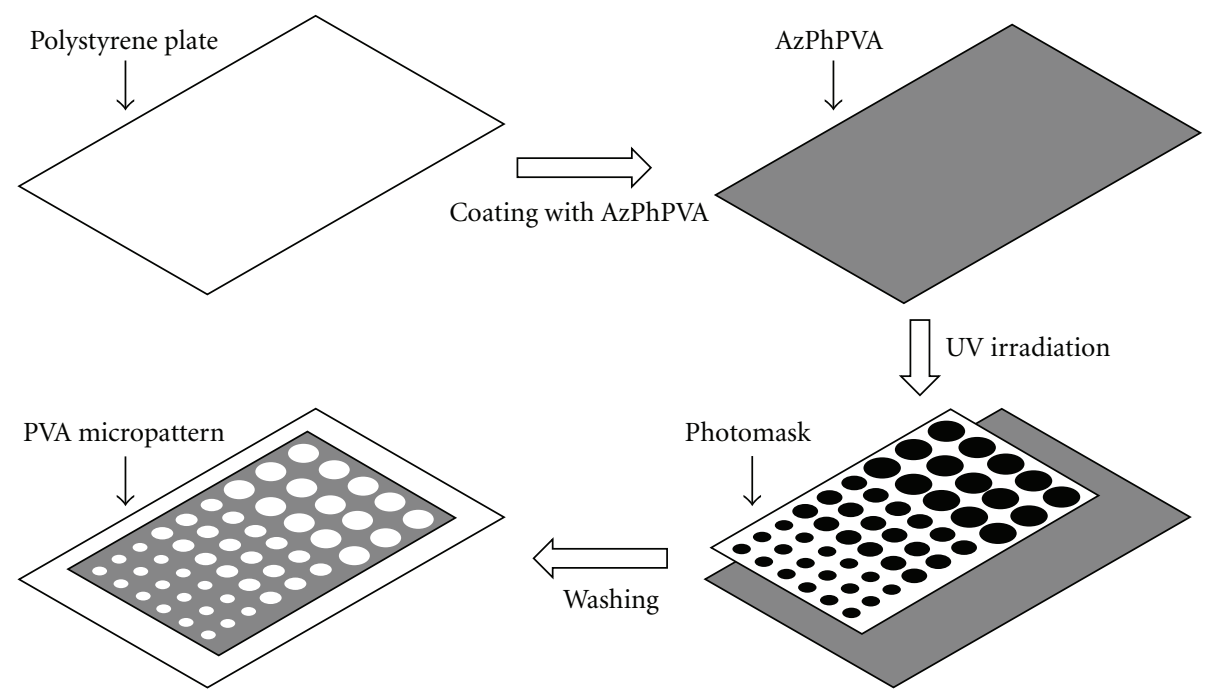

(a)

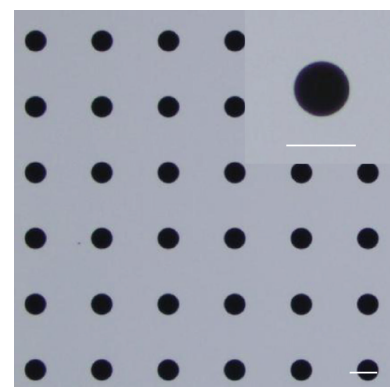

(b)

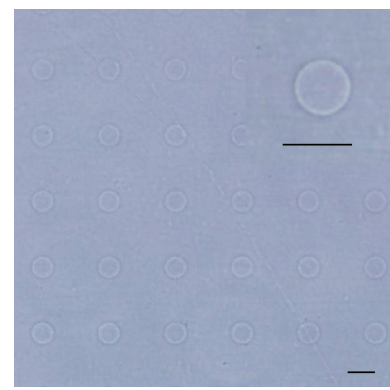

(e)

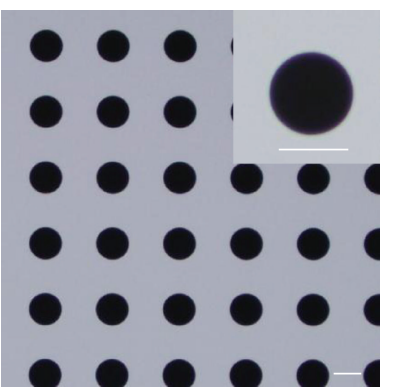

(c)

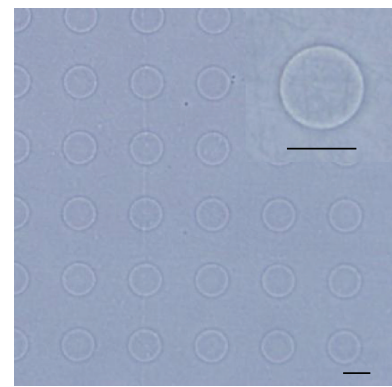

(f)

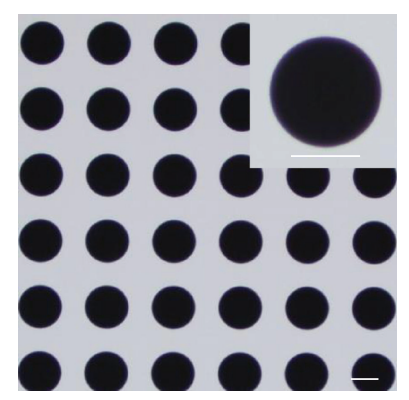

(d)

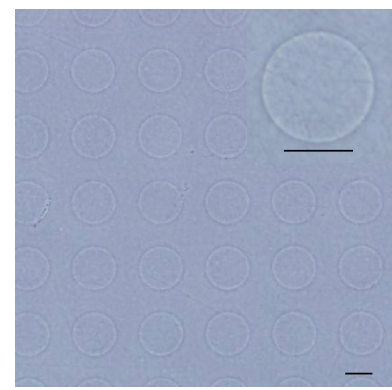

(g)

Figure 1: (a) Preparation scheme of the PVA-micropatterned surface. (b-d) Phase contrast micrographs of the photomask. (e-g) Phase contrast micrographs of the PVA-micropatterned polystyrene surface. Three types of circular polystyrene micropatterns with different diameters were formed and surrounded by PVA domains. Scale bars: $50 \mu \mathrm{m}$.

2.7. Alkaline Phosphatase (ALP) Staining. Cellular alkaline phosphatase (ALP) activity was assessed after culture for 7 and 21 days in osteogenic induction medium. The cultured cells were rinsed three times with phosphate-buffered saline (PBS) and fixed with $4 \%$ paraformaldehyde for $10 \mathrm{~min}$ at $4^{\circ} \mathrm{C}$. The fixed cells were soaked in $0.1 \%$ naphthol AS-MX phosphate (Sigma) and $0.1 \%$ fast red violet LB salt (Sigma) in $56 \mathrm{mM}$ 2-amino-2-methyl-1,3-propanediol ( $\mathrm{pH}$ 9.9, Sigma) for $10 \mathrm{~min}$ at room temperature, washed with $\mathrm{PBS}$, and then observed by an optical microscope with a DP-70 CCD camera (Olympus, Tokyo, Japan). The probability of MSC osteogenesis at different cell spreading areas was studied by calculating the percentage of MSCs that committed to an osteoblast lineage. MSCs positively stained were considered to be osteoblasts, and only single cells on each circular micropattern (as confirmed by nuclear staining) were counted. Three samples were used to calculate the means and standard deviations.

2.8. Statistical Analysis. A one-way analysis of variance (ANOVA) with Tukey's post hoc test for multiple comparisons was used for statistical analysis. A value of $P<.05$ was considered to be a statistically significant difference. 


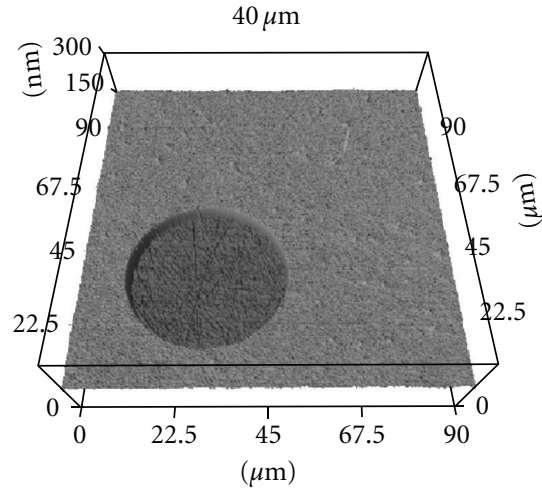

(a)

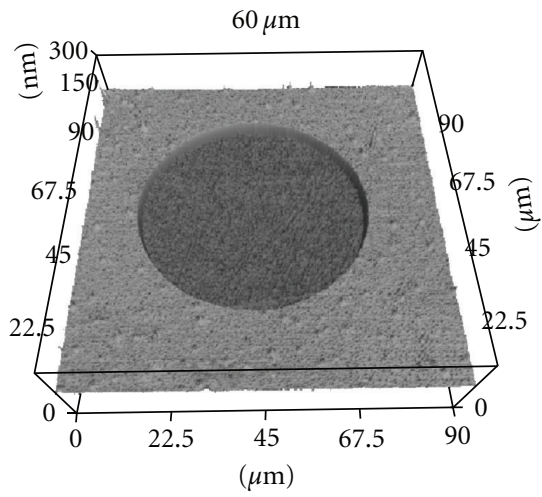

(b)

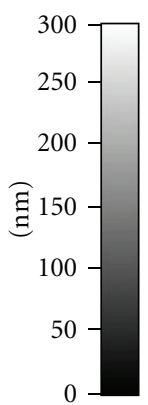

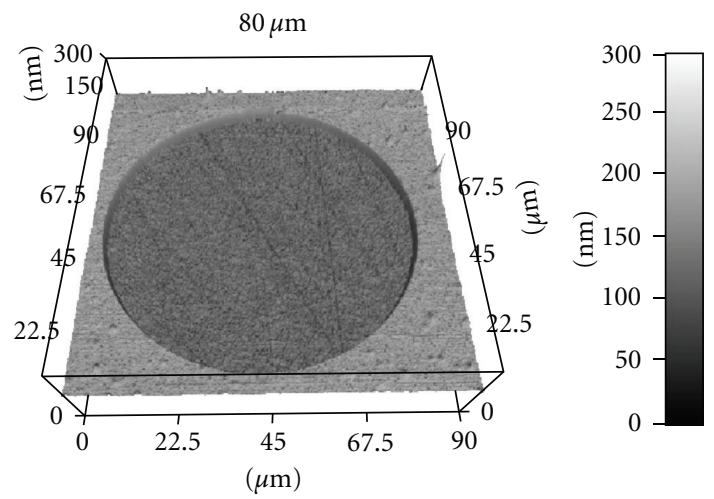

(c)

FIgURE 2: Three-dimensional AFM images of the three types of circular polystyrene micropatterns with different diameters measured in MilliQ water in contact mode.

\section{Results}

3.1. Preparation and Observation of PVA-Micropatterned Surfaces. The preparation scheme for the PVA-micropatterned polystyrene surface is illustrated in Figure 1(a). The AzPhPVA-coated plate was covered with a photomask and irradiated with UV light. The photomask had three different circular micropatterns with diameters of 40,60 , and $80 \mu \mathrm{m}$ (Figures 1(b)-1(d)). These circular micropatterns were UV blocking, and the underlying AzPhPVA was protected from UV light, unreacted during UV irradiation, and washed away by MilliQ water after UV irradiation. However, the AzPhPVA under the surrounding UV transparent domains was exposed to UV light, inter- and intramolecularly crosslinked, and grafted to the polystyrene surface. Therefore, three different circular polystyrene micropatterns were formed and surrounded by PVA domains (Figures $1(\mathrm{e})-1(\mathrm{~g})$ ). The circular polystyrene micropatterns promoted cell adhesion, whereas the surrounding PVA domains inhibited cell adhesion.

To measure the diameter of each circular polystyrene micropattern, the PVA-micropatterned polystyrene surfaces were observed by AFM in MilliQ water in contact mode. The three-dimensional images of the three circular polystyrene micropatterns are shown in Figure 2. The diameter and
TABle 1: The designed diameter of the circle on the photomask and the measured diameter and thickness of the prepared circular micropatterns, as determined by AFM section analysis. Data represent mean $\pm \mathrm{SD}(n=3)$.

\begin{tabular}{lcc}
\hline $\begin{array}{l}\text { Designed diameter } \\
(\mu \mathrm{m})\end{array}$ & $\begin{array}{c}\text { Measured diameter } \\
(\mu \mathrm{m})\end{array}$ & $\begin{array}{c}\text { Measured thickness } \\
(\mathrm{nm})\end{array}$ \\
\hline 40 & $39.2 \pm 0.5$ & $51.4 \pm 1.9$ \\
60 & $59.9 \pm 0.4$ & $53.6 \pm 2.8$ \\
80 & $79.8 \pm 0.6$ & $52.9 \pm 3.0$ \\
\hline
\end{tabular}

thickness of the circle were analyzed by section analysis of the acquired images (Table 1). The diameters of the circular micropatterns formed from the 40-, 60-, and 80$\mu \mathrm{m}$-diameter photomask micropatterns were $39.2 \pm 0.5$, $59.9 \pm 0.4$, and $79.8 \pm 0.6 \mu \mathrm{m}$, respectively. The circular polystyrene micropatterns had almost the same diameters as the designed photomask micropatterns. The thickness of the PVA layer was ranged from 51.4 to $53.6 \mathrm{~nm}$. Therefore, circular polystyrene micropatterns with different diameters were formed, and their structures could be controlled by designing the micropatterns of a photomask. 
$40 \mu \mathrm{m}$

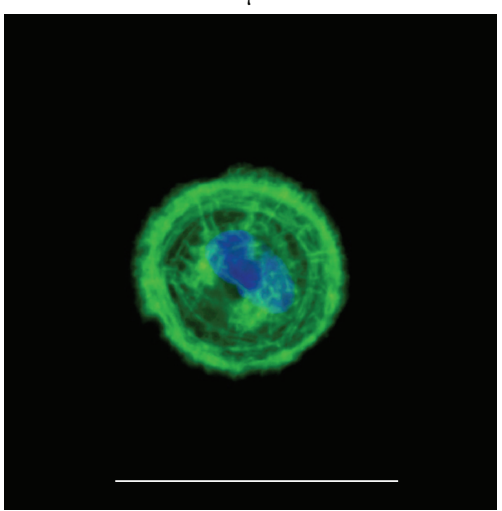

(a)

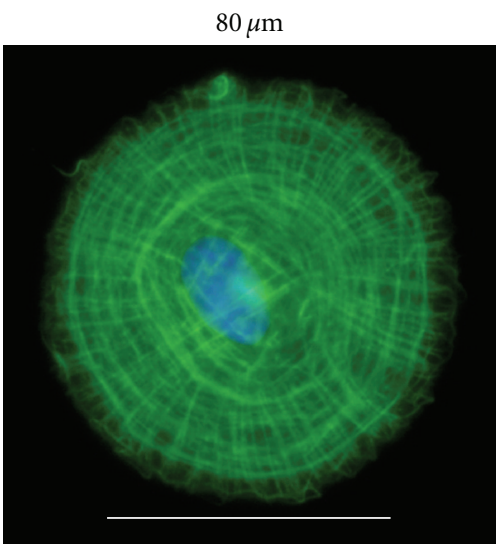

(c)

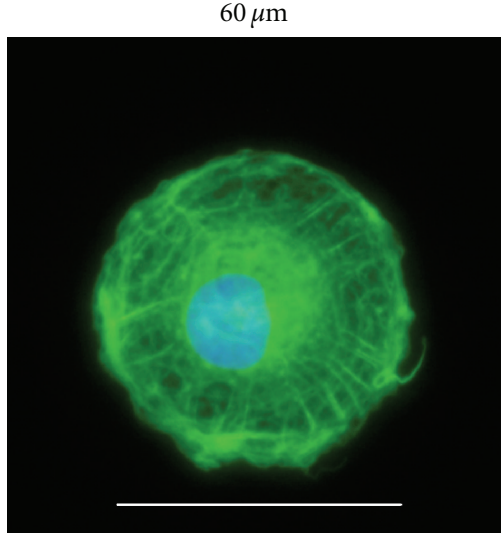

(b)

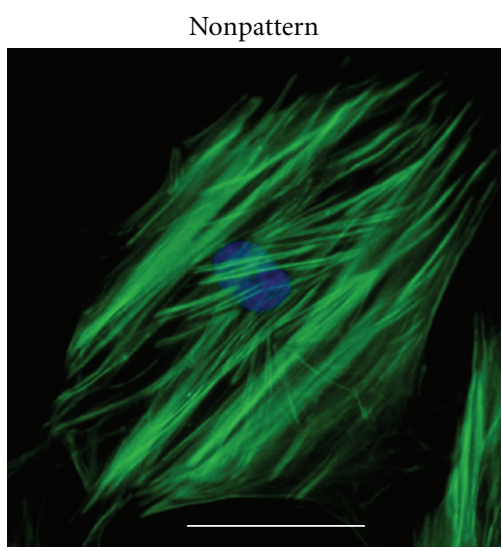

(d)

FIGURE 3: Fluorescence images of MSCs with different spreading areas stained for F-actin (green) and nuclei (blue) after culture in control medium for $6 \mathrm{~h}$. "Nonpattern" indicates a bare polystyrene surface without micropatterning and grafting of PVA. Scale bars: $50 \mu \mathrm{m}$.

3.2. Cell Adhesion and Spreading. The micropatterned surfaces were used for the culture of MSCs in control medium. After $6 \mathrm{~h}$ of culture, MSCs only adhered to cell-adhesive circular polystyrene micropatterns, and MSCs on nonadhesive PVA regions were removed by a medium change. About $85 \%$ of circular micropatterns were occupied by a single cell, as confirmed by cell nuclear staining using DAPI. Therefore, the heterogeneity of the cell population in routine cell culture could be reduced, and the behaviors and functions of MSCs could be studied at a single-cell level.

As shown in Figure 3, F-actin staining revealed that the spreading of MSCs followed the underlying circular polystyrene micropatterns and was confined by the surrounding non-adhesive PVA domains, whereas MSCs spread freely on bare polystyrene surfaces (nonpatterned). Interestingly, the assembly and organization of the actin structure of the MSCs were affected by the degree of cell spreading. Circular MSCs with the largest degree of spreading $(80 \mu \mathrm{m})$ mainly assembled actin in the radial and concentric directions of the circle. However, such organization of the actin structure weakened as the degree of cell spreading decreased. On the smallest circle $(40 \mu \mathrm{m})$, MSCs predominately assembled actin along their edges, between the adhesive polystyrene and non-adhesive PVA. The MSCs cultured on the bare polystyrene plate did not exhibit any regular organization.

\subsection{Adipogenic Differentiation of MSCs with Different Cell} Spreading Areas. MSCs were cultured on the micropatterns in adipogenic induction medium for 7 days. Some MSCs on micropatterns committed to adipocytes that contained lipid vacuoles. Lipid vacuoles were stained with Oil Red $\mathrm{O}$, a specific marker for adipogenic differentiation. Representative optical photographs of positively stained cells with different cell spreading areas are shown in Figure 4(a). The probabilities that MSCs with different degrees of cell spreading committed to adipocytes were evaluated. The cells containing lipid vacuoles positively stained by Oil Red $\mathrm{O}$ were considered to be adipocytes, and only single cells on each circular micropattern were counted. The results show that the probability of MSC adipogenesis was dependent on the degree of cell spreading (Figure 4(b)). The percentages of MSCs undergoing adipogenic differentiation were $45.3 \pm$ $3.4 \%, 26.3 \pm 3.4 \%$, and $14.7 \pm 4.2 \%$ for 40 - to $80-\mu \mathrm{m}$ circles and $12.4 \pm 2.0 \%$ for the bare polystyrene surface (nonpatterned). Therefore, the probability of adipogenic 

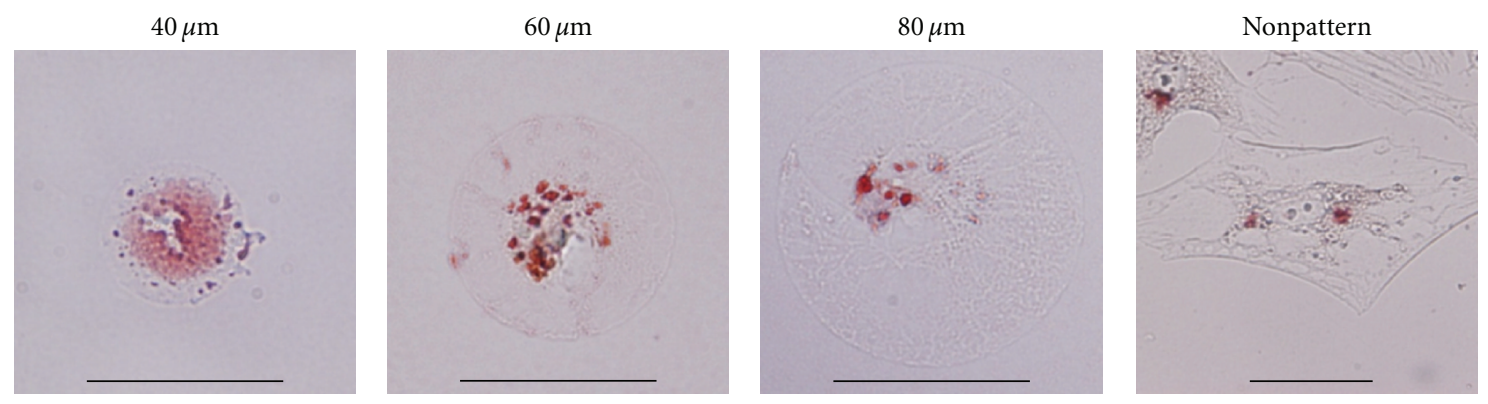

(a)

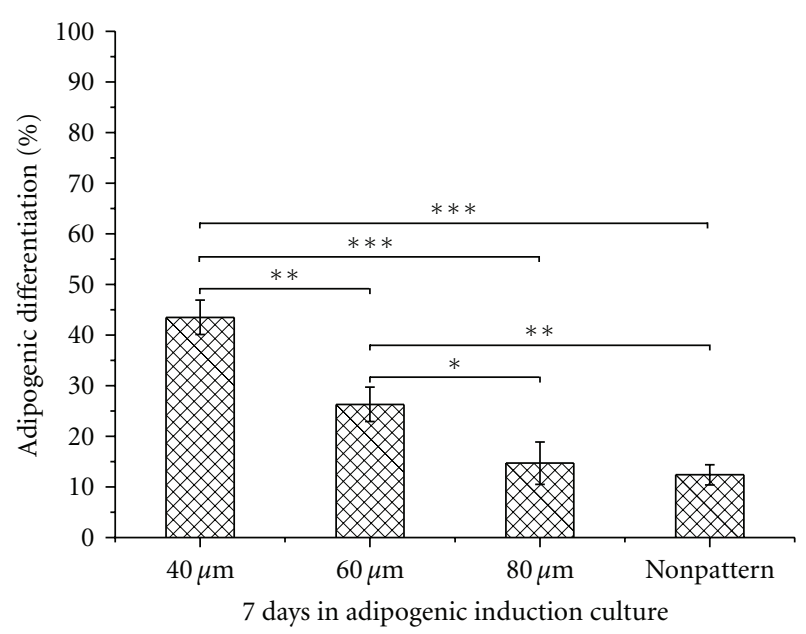

(b)

FIGURE 4: (a) Representative optical photographs of MSCs with different spreading areas stained by Oil Red O after culture in adipogenic induction medium for 7 days. (b) The percentage of adipogenic differentiation of MSCs with different spreading areas. Data represent mean $\pm \mathrm{SD}(n=3) .{ }^{*} P<.05,{ }^{* *} P<.01$, and ${ }^{* * *} P<.001$. Scale bars: $50 \mu \mathrm{m}$.

differentiation of MSCs decreased as the degree of cell spreading increased.

3.4. Osteogenic Differentiation of MSCs with Different Cell Spreading Areas. MSCs were cultured on the micropatterns in osteogenic induction medium for 7 and 21 days. The cells that were constrained on the micropatterns did not spread out from the micropatterns, even after 21 days of culture, while a confluent cell layer already formed on the bare polystyrene surface (Figure 5(a)). This result indicates that the micropatterned surfaces were stable and useful for longterm cell culture and assessment. Osteogenic differentiation was evaluated by ALP staining, a marker for osteogenesis. Representative optical photographs of positively stained cells are shown in Figure 5(b). The probabilities that MSCs with different degrees of cell spreading committed to osteoblasts are shown in Figure 5(c). The percentages of MSCs undergoing osteogenic differentiation were $13.0 \pm 2.2 \%, 28.3 \pm$ $3.0 \%$, and $41.2 \pm 1.9 \%$ on micropatterns with 40 - to 80 $\mu \mathrm{m}$ circles and $54.6 \pm 4.2 \%$ on the bare polystyrene surface (nonpatterned) after 7 days of osteogenic induction culture. The probability of osteogenic differentiation of MSCs increased as the degree of cell spreading was enhanced. After osteogenic induction culture for 21 days, the percentages of MSCs undergoing osteogenic differentiation were $17.5 \pm$ $3.5 \%, 40.2 \pm 3.8 \%$, and $53.9 \pm 5.4 \%$ on the micropatterns with 40 - to $80-\mu \mathrm{m}$ circles and $86.0 \pm 3.0 \%$ on the bare polystyrene surface (nonpatterned). Although the trend of the probability of osteogenic differentiation at 21 days was similar to that at 7 days, more cells underwent osteogenic differentiation after long-term culture. These results indicate that cell spreading facilitated osteogenic differentiation of MSCs, and long-term cell culture on the micropatterned surfaces was realized.

\section{Discussion}

In this study, different degrees of cell spreading with the same cell shape were controlled using micropatterning technology, and the effect of differential cell spreading area on the differentiation of MSCs was investigated on a micropatterned surface at the single-cell level.

Although many methods have been adopted to construct micropatterned surfaces for cell culture [28], few of them would be compatible with long-term cell culture (especially longer than 2 weeks), mainly because of the unstable nonfouling layer. Here, photo-reactive PVA was micropatterned on cell-culture polystyrene surfaces using photolithography. 

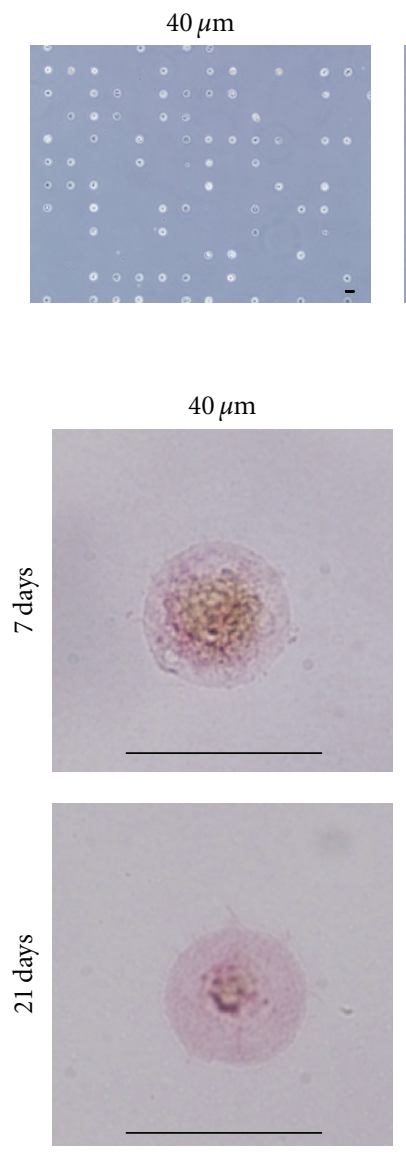
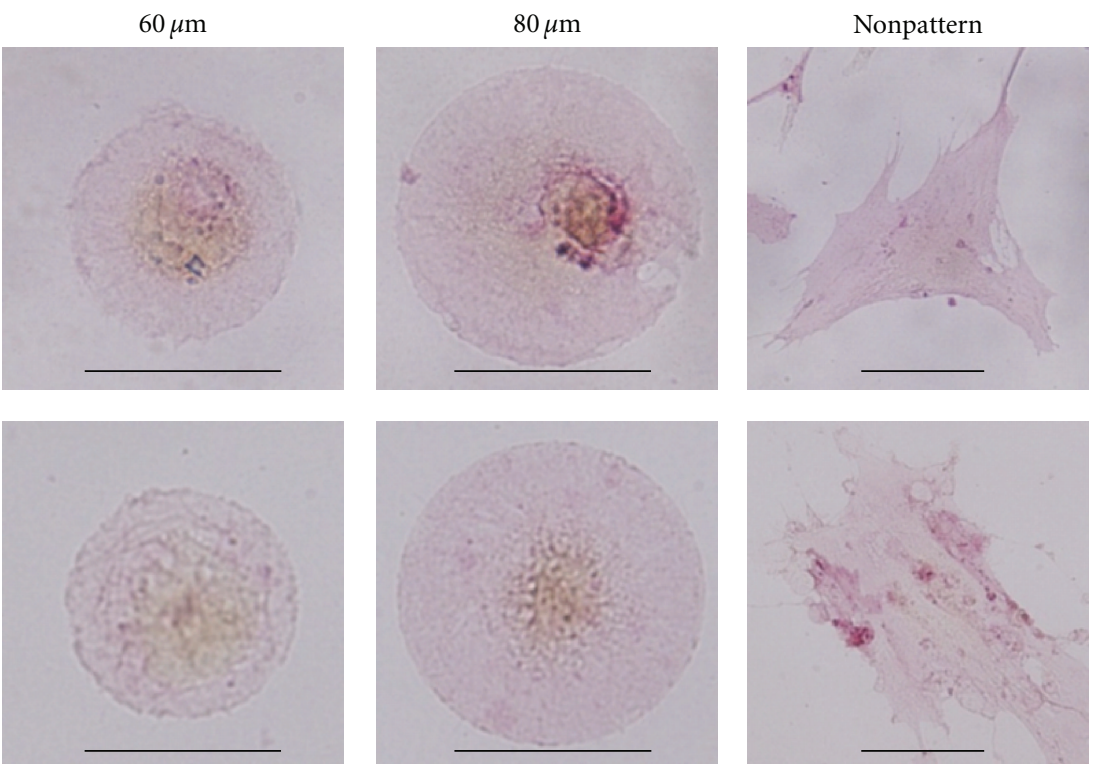

(b)

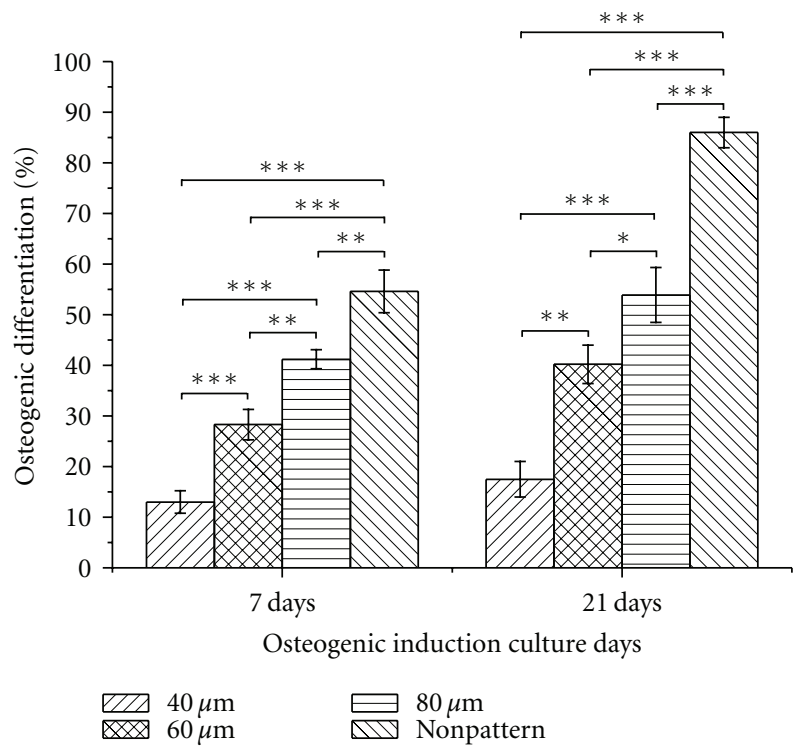

(c)

FIGURE 5: (a) Phase contrast photographs of MSCs after culture on micropatterned surfaces in osteogenic induction medium for 21 days. (b) Representative optical photographs of ALP staining of MSCs with different spreading areas after culture in osteogenic induction medium for 7 and 21 days. (c) The percentage of osteogenic differentiation of MSCs with different spreading areas after culture in osteogenic induction medium for 7 and 21 days. Data represent mean $\pm \operatorname{SD}(n=3) .{ }^{*} P<.05,{ }^{* *} P<.01$, and ${ }^{* * *} P<.001$. Scale bars: $50 \mu \mathrm{m}$. 
Because PVA molecules were intra- and intermolecularly crosslinked and covalently grafted to the polystyrene surface, PVA micropattern on polystyrene surface was stable during long-term cell culture. The thickness of non-adhesive PVA layer within nanometer scale is important for preventing protein adsorption and cell adhesion and for trapping single cell in polystyrene circle. Arima et al. [29] have reported that highly hydrated PVA layer with the thickness around $53.3 \mathrm{~nm}$ effectively resists serum proteins adsorption. The thickness of our micropatterned PVA layer was from 51.4 to $53.6 \mathrm{~nm}$, which protected cell spreading across the micropatterns. The PVA layer was controlled at nanometer scale to capture the single cell by means of different surface chemistry other than topography. Cell adhesion result showed that $\sim 85 \%$ of circular polystyrene domain was occupied by single cell. However, the surface topography will affect cell behavior if the PVA layer increases to micrometer level which is similar to microwell structure. Multilayer cells are likely to be trapped in such PVA microwell. It has been reported that microwell structures were adopted to prepare multilayer cell spheroids [30, 31]. Therefore, nanometer-thick PVA micropattern on polystyrene surface is compatible with single-cell array formation and long-term cell culture.

With the advantage of micropatterns, cell adhesion, shape, and spreading were regulated at the single-cell level. Hence, the complexity of cell-cell interactions and the heterogeneity of the cell population during routine cell culture were significantly reduced [32]. The behaviors and functions of individual MSCs could be investigated and compared at specific conditions with a fixed shape but varied spreading areas. The actin structure of MSCs was affected by the degree of cell spreading. Well-organized stress fibers appeared in MSCs that adhered to the large circular micropatterns. In contrast, MSCs confined to small circular micropatterns assembled thicker actin filaments at the edge than in the interior, a phenomenon suggesting that cells were maximizing their spreading. It has been reported that actin structures play an important role in the differentiation of MSCs [33-35]. Thus, the different actin arrangements suggest a tight relationship among cell spreading, the cytoskeletal network, and stem cell functions.

The long-term effects of different degrees of cell spreading on the differentiation of isolated individual MSCs without direct cell-cell interactions were directly compared on the same PVA-micropatterned polystyrene surface. This way, uncertain factors arising from separate cell cultures and heterogeneity of cell population in common cell culture were greatly reduced. The differentiation of MSCs strongly depended on the degree of cell spreading. However, osteogenic and adipogenic differentiation of MSCs exhibited opposite correlations. Namely, cell spreading promoted osteogenic differentiation but suppressed adipogenic differentiation of MSCs. This result is consistent with other reports $[14,36]$, which also suggests that cell spreading favors osteogenic differentiation but inhibits adipogenic differentiation of MSCs. The reason may be that cytoskeletal contractility was enhanced with increased cell spreading [37, 38 ], and high contractility favors osteogenesis, whereas lower contractility enhanced the adipogenesis of MSCs $[39,40]$.

\section{Conclusions}

Different degrees of cell spreading with the same cell shape were established on PVA-micropatterned polystyrene surfaces. The assembly and organization of actin filaments depended on the degree of cell spreading. MSCs on larger circular micropatterns exhibited a more highly ordered actin structure, whereas MSCs on small circular micropatterns mainly aligned actin fibers along the edge between cell-adhesive polystyrene and non-adhesive PVA. The distinct degree of cell spreading also had an effect on the differentiation of MSCs. Osteogenic differentiation of MSCs increased with increased cell spreading. In contrast, adipogenic differentiation of MSCs decreased with increased cell spreading. This micropatterning technique provides a convenient method to directly compare stem cell functions for both short- and long-term cell culture.

\section{Acknowledgment}

This work was supported by World Premier International Research Center Initiative on Materials Nanoarchitectonics from the Ministry of Education, Culture, Sports, Science and Technology, Japan.

\section{References}

[1] F. M. Watt and B. L. M. Hogan, "Out of eden: stem cells and their niches," Science, vol. 287, no. 5457, pp. 1427-1430, 2000.

[2] M. P. Lutolf, P. M. Gilbert, and H. M. Blau, "Designing materials to direct stem-cell fate," Nature, vol. 462, no. 7272, pp. 433-441, 2009.

[3] F. Guilak, D. M. Cohen, B. T. Estes, J. M. Gimble, W. Liedtke, and C. S. Chen, "Control of stem cell fate by physical interactions with the extracellular matrix," Cell Stem Cell, vol. 5, no. 1, pp. 17-26, 2009.

[4] T. Hoshiba, N. Kawazoe, T. Tateishi, and G. Chen, "Development of stepwise osteogenesis-mimicking matrices for the regulation of mesenchymal stem cell functions," Journal of Biological Chemistry, vol. 284, no. 45, pp. 31164-31173, 2009.

[5] T. Hoshiba, N. Kawazoe, T. Tateishi, and G. Chen, "Development of extracellular matrices mimicking stepwise adipogenesis of mesenchymal stem cells," Advanced Materials, vol. 22, no. 28, pp. 3042-3047, 2010.

[6] L. Guo, N. Kawazoe, Y. Fan et al., "Chondrogenic differentiation of human mesenchymal stem cells on photoreactive polymer-modified surfaces," Biomaterials, vol. 29, no. 1, pp. 23-32, 2008.

[7] L. Guo, N. Kawazoe, T. Hoshiba, T. Tateishi, G. Chen, and $\mathrm{X}$. Zhang, "Osteogenic differentiation of human mesenchymal stem cells on chargeable polymer-modified surfaces," Journal of Biomedical Materials Research. Part A, vol. 87, no. 4, pp. 903912, 2008.

[8] N. Jaiswal, S. E. Haynesworth, A. I. Caplan, and S. P. Bruder, "Osteogenic differentiation of purified, culture-expanded human mesenchymal stem cells in vitro," Journal of Cellular Biochemistry, vol. 64, no. 2, pp. 295-312, 1997.

[9] M. F. Pittenger, A. M. Mackay, S. C. Beck et al., "Multilineage potential of adult human mesenchymal stem cells," Science, vol. 284, no. 5411, pp. 143-147, 1999. 
[10] K. Alberti, R. E. Davey, K. Onishi et al., "Functional immobilization of signaling proteins enables control of stem cell fate," Nature Methods, vol. 5, no. 7, pp. 645-650, 2008.

[11] M. R. Doran, B. D. Markway, I. A. Aird et al., "Surfacebound stem cell factor and the promotion of hematopoietic cell expansion,” Biomaterials, vol. 30, no. 25, pp. 4047-4052, 2009.

[12] A. J. Engler, S. Sen, H. L. Sweeney, and D. E. Discher, "Matrix elasticity directs stem cell lineage specification," Cell, vol. 126, no. 4, pp. 677-689, 2006.

[13] M. J. Dalby, N. Gadegaard, R. Tare et al., "The control of human mesenchymal cell differentiation using nanoscale symmetry and disorder," Nature Materials, vol. 6, no. 12, pp. 997-1003, 2007.

[14] R. McBeath, D. M. Pirone, C. M. Nelson, K. Bhadriraju, and C. S. Chen, "Cell shape, cytoskeletal tension, and RhoA regulate stem cell lineage commitment," Developmental Cell, vol. 6, no. 4, pp. 483-495, 2004.

[15] R. Peerani, B. M. Rao, C. Bauwens et al., "Niche-mediated control of human embryonic stem cell self-renewal and differentiation," EMBO Journal, vol. 26, no. 22, pp. 4744-4755, 2007.

[16] J. T. Connelly, J. E. Gautrot, B. Trappmann et al., "Actin and serum response factor transduce physical cues from the microenvironment to regulate epidermal stem cell fate decisions," Nature Cell Biology, vol. 12, no. 7, pp. 711-718, 2010.

[17] K. Bhadriraju and L. K. Hansen, "Extracellular matrix- and cytoskeleton-dependent changes in cell shape and stiffness," Experimental Cell Research, vol. 278, no. 1, pp. 92-100, 2002.

[18] E. Szabo, T. Feng, E. Dziak, and M. Opas, "Cell adhesion and spreading affect adipogenesis from embryonic stem cells: the role of calreticulin," Stem Cells, vol. 27, no. 9, pp. 2092-2102, 2009.

[19] G. Chen, N. Kawazoe, Y. Fan, Y. Ito, and T. Tateishi, "Grid pattern of nanothick microgel network," Langmuir, vol. 23, no. 11, pp. 5864-5867, 2007.

[20] M. Théry, V. Racine, A. Pépin et al., "The extracellular matrix guides the orientation of the cell division axis," Nature Cell Biology, vol. 7, no. 10, pp. 947-953, 2005.

[21] M. Théry, V. Racine, M. Piel et al., "Anisotropy of cell adhesive microenvironment governs cell internal organization and orientation of polarity," Proceedings of the National Academy of Sciences of the United States of America, vol. 103, no. 52, pp. 19771-19776, 2006.

[22] J. E. Gautrot, B. Trappmann, F. Oceguera-Yanez et al., "Exploiting the superior protein resistance of polymer brushes to control single cell adhesion and polarisation at the micron scale," Biomaterials, vol. 31, no. 18, pp. 5030-5041, 2010.

[23] R. G. Thakar, Q. Cheng, S. Patel et al., "Cell-shape regulation of smooth muscle cell proliferation," Biophysical Journal, vol. 96, no. 8, pp. 3423-3432, 2009.

[24] C. S. Chen, M. Mrksich, S. Huang, G. M. Whitesides, and D. E. Ingber, "Geometric control of cell life and death," Science, vol. 276, no. 5317, pp. 1425-1428, 1997.

[25] L. Q. Wan, S. M. Kang, G. Eng et al., "Geometric control of human stem cell morphology and differentiation," Integrative Biology, vol. 2, no. 7-8, pp. 346-353, 2010.

[26] N. Kawazoe, L. Guo, M. J. Wozniak et al., "Adipogenic differentiation of mesenchymal stem cells on micropatterned polyelectrolyte surfaces," Journal of Nanoscience and Nanotechnology, vol. 9, no. 1, pp. 230-239, 2009.
[27] H. Lu, L. Guo, M. J. Wozniak et al., "Effect of cell density on adipogenic differentiation of mesenchymal stem cells," Biochemical and Biophysical Research Communications, vol. 381, no. 3, pp. 322-327, 2009.

[28] D. Falconnet, G. Csucs, H. Michelle Grandin, and M. Textor, "Surface engineering approaches to micropattern surfaces for cell-based assays," Biomaterials, vol. 27, no. 16, pp. 3044-3063, 2006.

[29] Y. Arima, M. Kawagoe, M. Furuta, M. Toda, and H. Iwata, "Effect of swelling of poly(vinyl alcohol) layers on complement activation," Biomaterials, vol. 31, pp. 6926-6933, 2010.

[30] J. Y. Karp, J. Yeh, G. Eng et al., "Controlling size, shape and homogeneity of embryoid bodies using poly(ethylene glycol) microwells," Lab on a Chip, vol. 7, pp. 786-794, 2007.

[31] Y. Y. Choi, B. G. Chung, D. H. Lee, A. Khademhosseini, J. H. Kim, and S. H. Lee, "Controlled-size embryoid body formation in concave microwell arrays," Biomaterials, vol. 31, pp. 4296-4303, 2010.

[32] R. Singhvi, A. Kumar, G. P. Lopez et al., "Engineering cell shape and function," Science, vol. 264, no. 5159, pp. 696-698, 1994.

[33] C. Y. Tay, H. Yu, M. Pal et al., "Micropatterned matrix directs differentiation of human mesenchymal stem cells towards myocardial lineage," Experimental Cell Research, vol. 316, no. 7, pp. 1159-1168, 2010.

[34] J. P. Rodríguez, M. González, S. Ríos, and V. Cambiazo, "Cytoskeletal organization of human mesenchymal stem cells (MSC) changes during their osteogenic differentiation," Journal of Cellular Biochemistry, vol. 93, no. 4, pp. 721-731, 2004.

[35] G. Yourek, M. A. Hussain, and J. J. Mao, "Cytoskeletal changes of mesenchymal stem cells during differentiation," ASAIO Journal, vol. 53, no. 2, pp. 219-228, 2007.

[36] M. Guvendiren and J. A. Burdick, "The control of stem cell morphology and differentiation by hydrogel surface wrinkles," Biomaterials, vol. 31, no. 25, pp. 6511-6518, 2010.

[37] P. Roca-Cusachs, J. Alcaraz, R. Sunyer, J. Samitier, R. Farré, and D. Navajas, "Micropatterning of single endothelial cell shape reveals a tight coupling between nuclear volume in G1 and proliferation," Biophysical Journal, vol. 94, no. 12, pp. 49844995, 2008.

[38] M. Théry, A. Pépin, E. Dressaire, Y. Chen, and M. Bornens, "Cell distribution of stress fibres in response to the geometry of the adhesive environment," Cell Motility and the Cytoskeleton, vol. 63, no. 6, pp. 341-355, 2006.

[39] K. A. Kilian, B. Bugarija, B. T. Lahn, and M. Mrksich, "Geometric cues for directing the differentiation of mesenchymal stem cells," Proceedings of the National Academy of Sciences of the United States of America, vol. 107, no. 11, pp. 4872-4877, 2010.

[40] S. A. Ruiz and C. S. Chen, "Emergence of patterned stem cell differentiation within multicellular structures," Stem Cells, vol. 26, no. 11, pp. 2921-2927, 2008. 

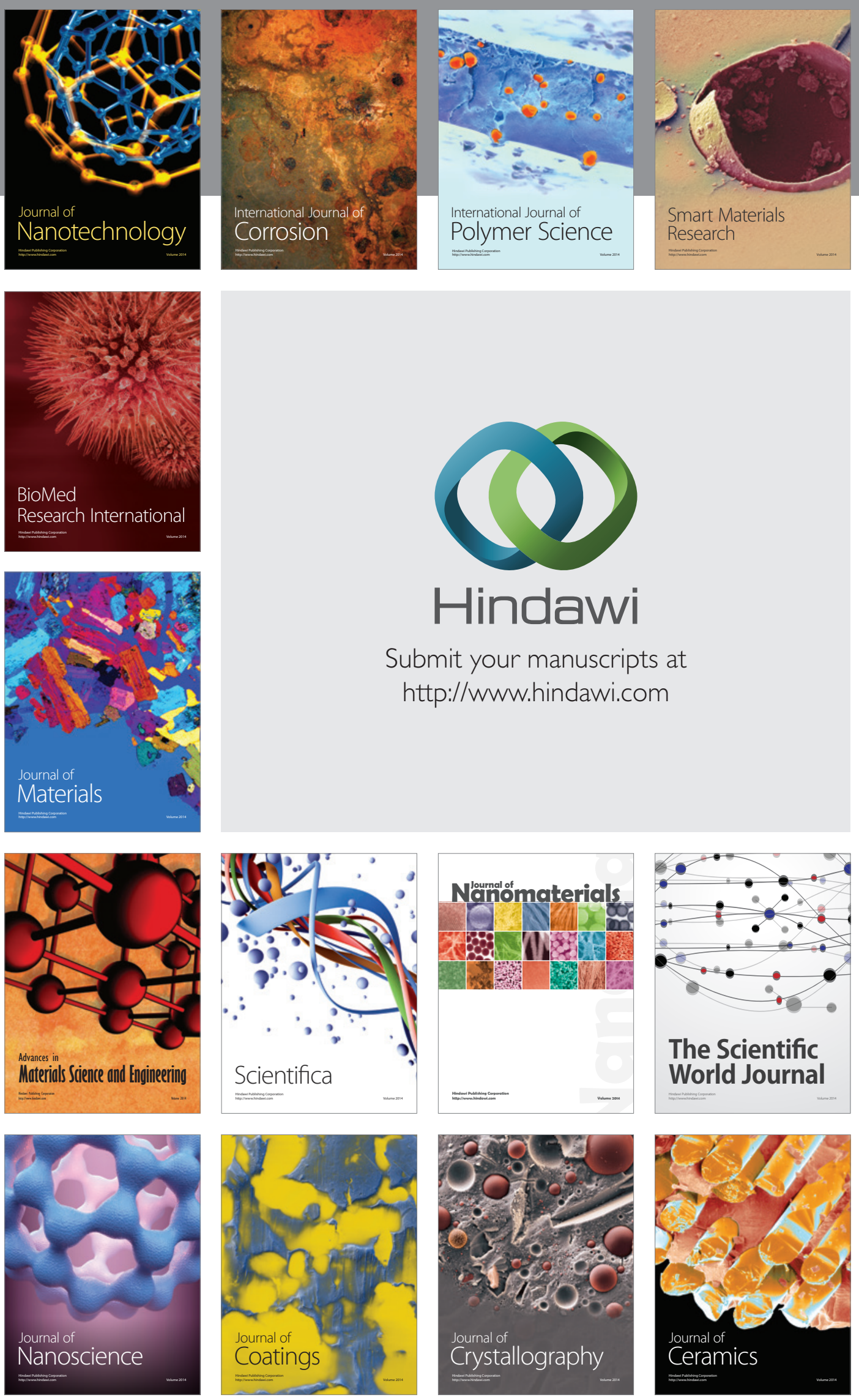

The Scientific World Journal

Submit your manuscripts at

http://www.hindawi.com

\section{World Journal}

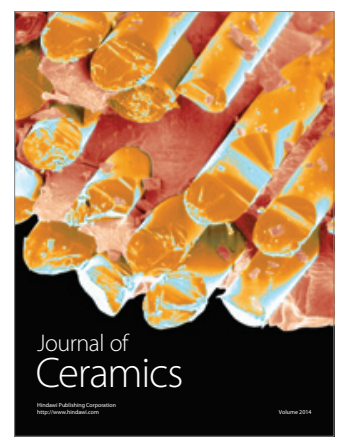

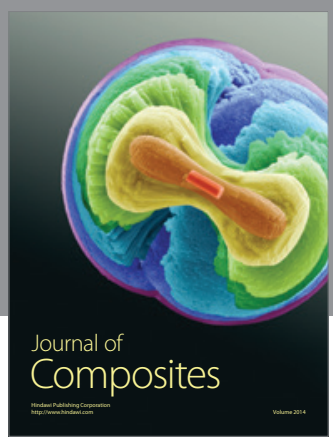
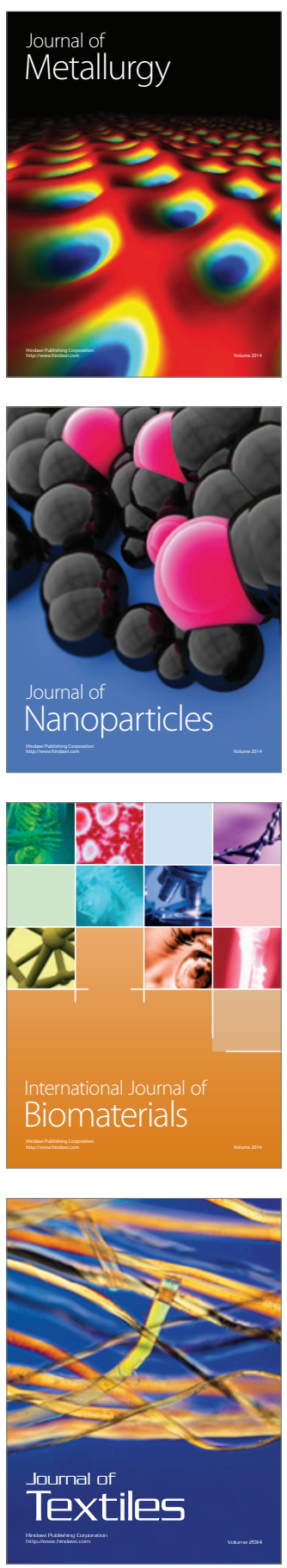